\title{
O ENSINO DA ORTOGRAFIA EM LIVRO DIDÁTICO DE LÍNGUA PORTUGUESA PARA O ENSINO FUNDAMENTAL
}

\author{
Liliane Ieda Dresch Tomasi ${ }^{1}$ \\ Clarice Cristina Corbari ${ }^{2}$
}

\begin{abstract}
Resumo: Este artigo constitui um recorte de investigação com o objetivo de verificar a forma como é abordada a ortografia em uma coleção de livros didáticos de Língua Portuguesa para o Ensino Fundamental. Com base em pressupostos teórico-metodológicos propostos por autores como Cagliari (2002), Morais (2003), Morais e Silva (2007) e Melo (2007), que defendem uma abordagem reflexiva do ensino e da aprendizagem de ortografia, faz-se um levantamento de como a ortografia é abordada na coleção "Português: linguagens", de Cereja e Magalhães (2015), amplamente utilizada em escolas públicas da região Oeste do Paraná, buscando verificar se o material propóe atividades baseadas em uma perspectiva de reflexão sobre as regularidades e irregularidades da norma ortográfica ou se ainda está vinculado a uma abordagem tradicional.
\end{abstract}

Palavras-chave: Língua Portuguesa. Livro didático. Ortografia.

\section{THE TEACHING OF SPELLING IN TEXTBOOKS FOR TEACHING PORTUGUESE IN THE ELEMENTARY SCHOOL}

\begin{abstract}
This paper constitutes part of an investigation aiming at verifying the approach of spelling in a textbook collection for teaching Portuguese in the Elementary School. Based on theoreticalmethodological principles proposed by authors such as Cagliari (2002), Morais (2003), Morais and Silva (2007) and Melo (2007), who advocate a reflexive approach of the teaching-learning of spelling, we investigate how spelling is addressed in the collection "Português: linguagens", by Cereja and Magalhães (2015), which is widely used in state schools in the West of Paraná, in order to examine whether the material proposes activities based on a perspective of reflecting on the regularities and irregularities of spelling or it is still linked to a traditional approach.
\end{abstract}

Keywords: Portuguese. Textbooks. Spelling.

1 Mestranda do Programa de Pós-Graduação Mestrado Profissional em Letras (ProfLetras) da Universidade Federal do Oeste do Paraná (Unioeste). Professora da rede pública de ensino do Paraná.

2 Doutora em Letras. Professora do Curso de Graduação em Letras e do Programa de PósGraduação Mestrado Profissional em Letras (ProfLetras) da Universidade Federal do Oeste do Paraná (Unioeste). 


\section{Introduçáo}

No Brasil, o ensino de Língua Portuguesa se pauta nas orientações contidas nos Parâmetros Curriculares Nacionais (doravante PCN) (BRASIL, 1998) e, mais recentemente, na Base Nacional Comum Curricular (doravante BNCC) (BRASIL, 2018), e no Estado do Paraná, nas Diretrizes Curriculares da Educação Básica: Língua Portuguesa (doravante DCE) (PARANÁ, 2008), que focalizam o trabalho com os gêneros textuais, na perspectiva de desenvolver competências de uso da língua em diversas situações de comunicação. É a partir dos gêneros, portanto, que se direciona todo o trabalho com a língua, incluindo a análise linguística, assumindo-se que o ensino orientado pela gramática tradicional não mais atende às novas necessidades da sociedade, dado que essa visão considera a língua meramente como um sistema de regras - privilegiando-se a norma padrão - e desconsidera as variedades linguísticas e contextuais, ou seja, a língua em uso.

Até aproximadamente duas décadas atrás, os livros didáticos, de modo geral, não contemplavam gêneros variados e nem questões reflexivas de estudo do texto (geralmente, tratava-se de questões que exigiam a localização de informações pontuais no texto); as atividades de produção textual não passavam de exercícios descontextualizados de escrita (redação escolar); e a gramática era trabalhada de forma isolada nas unidades, em que se repetiam exercícios de completar lacunas ou classificar palavras ou partes das sentenças (classes de palavras, funções gramaticais etc.). Porém, com a emergência da teoria dos gêneros textuais, a noção de texto foi efetivamente ampliada, e muitos materiais que costumavam apresentar textos "didatizados" para o ensino de determinado conteúdo passaram a contemplar textos autênticos, que pertencem a uma esfera de circulação real e possuem um interlocutor real. Esse novo contexto passou, portanto, a exigir de professores e de autores de materiais didáticos uma nova visão de língua e de ensino para a realização de um trabalho pautado nas teorias vigentes. No entanto, no que tange ao trabalho de análise linguística, é possível verificar lacunas em muitos materiais didáticos, especialmente por ainda apresentar vínculos com a abordagem tradicional.

Com relação à abordagem da ortografia, que é o objeto deste artigo, os PCN para o Ensino Fundamental postulam que

É possível desenvolver um trabalho que permita ao aluno descobrir o funcionamento do sistema grafo-fonêmico da língua e as convenções ortográficas, analisando as relações entre a fala e a escrita, as restrições que o contexto impõe ao emprego das letras, os aspectos morfossintáticos, tratando a ortografia como porta de entrada para uma reflexão a respeito da língua, particularmente, da modalidade escrita (BRASIL, 1998, p. 85).

Os PCN propõem desenvolver estratégias de ensino que privilegiem tanto a regularidade quanto a irregularidade das formas ortográficas. Para o referido documento, é importante que as estratégias didáticas para o ensino da ortografia se articulem em torno de dois eixos básicos, a saber:

- o da distinção entre o que é "produtivo" e o que é "reprodutivo" na notação da ortografia da língua, permitindo no primeiro caso o descobrimento 
explícito de regras geradoras de notações corretas e, quando não, a consciência de que não há regras que justifiquem as formas corretas fixadas pela norma; e - a distinção entre palavras de uso freqüente e infreqüente na linguagem escrita impressa (BRASIL, 1998, p. 57).

A BNCC, documento normativo de abrangência nacional que estabelece as aprendizagens essenciais que o educando precisa desenvolver ao longo de cada etapa ou modalidade de ensino, sinaliza, no que tange à fase escolar do $6^{\circ}$ ao $9^{\circ}$ ano, o trabalho com a fono-ortografia associado à abordagem de questões sintáticas e notacionais, nas práticas de produção e revisão de textos escritos. O documento é mais específico no que concerne ao ensino de ortografia quando indica a habilidade de "escrever palavras com correção ortográfica, obedecendo as convenções da língua escrita" (BRASIL, 2018, s.p.) para o $6^{\circ}$ e o $7^{\circ}$ anos, apontando as seguintes diretrizes:

\begin{abstract}
$\mathrm{Na}$ elaboração do currículo, sugere-se que o desenvolvimento desta habilidade venha sempre associado a práticas de produção e/ou revisão de textos, especialmente em situações públicas e formais em que a ortografia é requisito necessário. A progressão curricular pode se basear: (a) nos tópicos de ortografia a serem previstos para os dois anos em jogo, iniciando-se com as regularidades e prosseguindo com as irregularidades; (b) no grau de complexidade dos gêneros e textos programados para as práticas de produção e/ou revisão envolvidas nesse estudo; (c) no nível de autonomia que se pretende levar o aluno a conquistar a cada etapa (BRASIL, 2018, s.p.).
\end{abstract}

Nas DCE, a referência ao trabalho com a ortografia aparece negligenciado, limitado à orientação para que o professor considere, no trabalho com a escrita, questões normativas como "[...] as normas de sintaxe, bem como a pontuação, ortografia, paragrafação" (PARANÁ, 2008, p. 70) ou "[...] ortografia, concordância verbal/nominal, sujeito, predicado, complemento, regência, vícios da linguagem" (PARANÁ, 2008, p. 80). Ou seja, as DCE não propõem qualquer reflexão sobre a norma ortográfica, mas apenas sugerem observar a correção ortográfica na produção textual.

Neste artigo, pretende-se problematizar a forma como uma coleção de livros didáticos adotada em escolas públicas do Paraná, especialmente na região Oeste, aborda o ensino da ortografia. Com base em leituras de autores como Cagliari (2002), Morais (2003), Morais e Silva (2007) e Silva (2010), objetiva-se investigar se o material propõe atividades baseadas em uma perspectiva de reflexão sobre as regularidades e irregularidades da norma ortográfica ou se ainda segue uma perspectiva tradicional, pautada principalmente na memorização de regras. Além disso, busca-se verificar se o material é abundante em exercícios de sistematização da norma ortográfica.

\title{
Norma ortográfica e ensino
}

A norma ortográfica é uma convenção que unifica a grafia das palavras. Conforme Morais (2003, p. 19), "a forma correta das palavras é sempre uma 
convenção, algo que se define socialmente". A função da ortografia é padronizar a escrita e neutralizar as variações linguísticas, de modo a permitir "[...] uma circulação da escrita em diferentes épocas e lugares, sem que os leitores tenham que se preocupar com as pronúncias dos autores" (CAGLIARI, 2002, p. 12).

É função da escola ensinar a norma ortográfica. Segundo Morais (2003, p. 17-18), "[...] a escola cobra do aluno que ele escreva certo, mas cria poucas oportunidades para refletir com eles sobre as dificuldades da língua". Para esse autor, a ortografia é uma importante fonte de fracasso escolar e de discriminação social. Nesse sentido, "[...] ao negligenciar sua tarefa de ensinar ortografia, a escola contribui para a manutenção das diferenças sociais, já que ajuda a preservar a distinção entre bons e maus usuários da língua" (MORAIS, 2003, p. 24). Silva (2010) afirma que a não familiarização com a norma ortográfica torna o usuário da língua vítima de estigma e de preconceito linguístico-social, pois sua natureza normativa não permite transgressões (a não ser quando a transgressão está a serviço da produção de sentidos).

Morais e Silva (2007) apontam três maneiras distintas de abordar a ortografia no ensino de Língua Portuguesa: a) tradicional (por meio de memorização); b) progressista ou espontaneísta; e c) reflexiva. O ensino tradicional da ortografia, calcado no estudo descontextualizado e na memorização de regras, não preocupado com a formação de alunos leitores e produtores de texto, teve o rechaço de um considerável número de pesquisadores e professores, o que levou a outro extremo: a aquilo que Morais $(2003$, p. 23) chama de "[...] uma atitude de negligência e de preconceito para com o ensino de ortografia". Como consequência, "[...] alguns professores passaram a adotar uma postura espontaneísta com relação ao ensinoaprendizagem da ortografia, acreditando que os alunos aprenderiam a escrever certo 'naturalmente', através do contato com livros e outros materiais escritos" (MORAIS, 2003, p. 23).

Morais (2000; 2003), Melo (2007) e Morais e Silva (2007) acreditam na possibilidade de ensinar ortografia em uma perspectiva construtivista. Segundo Morais (2003, p. 24), "[...] um ensino sistemático, que pouco a pouco leve à reflexão sobre as diferentes dificuldades de nossa ortografia, ajudará a criança exatamente a se tornar melhor escritora". Essa seria uma alternativa ao fracasso da abordagem na perspectiva progressista, em que "[...] deixa-se de ensinar e continua-se cobrando a correção ortográfica. Não assumindo nem uma nem outra posição, consideramos uma terceira perspectiva, segundo a qual a escola deve ensinar ortografia, mas tratando-a como um objeto de reflexão" (MORAIS; SILVA, 2007, p. 61-62).

Cagliari (2002) e Morais (2003), entre outros pesquisadores do tema, defendem a importância de equilibrar duas vertentes: produzir textos e dominar a ortografia. Para isso, o indivíduo que está no processo de aprendizagem precisa compreender a ortografia como uma convenção que tem por objetivo uniformizar a escrita e facilitar a comunicação escrita.

Os erros ortográficos têm naturezas diferentes, envolvendo regularidades e irregularidades. De acordo com Morais (2003, p. 21): "Em muitos casos há regras, 
princípios orientadores que nos permitem prever, com segurança, a grafia correta. Em outros casos, é preciso memorizar. Ao ensinar ortografia, o professor precisa então levar em conta as peculiaridades de cada dificuldade ortográfica."

Ainda segundo esse autor,

O entendimento do que é regular e do que é irregular em nossa ortografia me parece fundamental para o professor organizar seu ensino. Se percebermos que os erros ortográficos têm causas distintas, podemos abraçar a idéia de que a superação de erros diferentes requer estratégias de ensino-aprendizagem diferentes. Isto é, para avançar na superação de erros distintos, o aluno precisa ser ajudado a usar diferentes modos de raciocinar sobre as palavras (MORAIS, 2003, p. 28)

Melo (2007) também entende que as questões ortográficas apresentam regularidades e irregularidades, e que o trabalho com ortografia requer a intervenção do professor para auxiliar os estudantes na compreensão e, muitas vezes, memorização do que deve ser aprendido.

Nos casos que envolvem regularidades, é preciso ajudar os alunos a compreender (e não decorar) as regras subjacentes. Como exemplos de regras que o aluno precisa compreender para escrever conforme a norma padrão, destacamse dois tipos: a) palavras cuja grafia é definida pela localização do som no interior da palavra (regularidade contextual); e b) palavras cuja grafia é relacionada a sua natureza gramatical (regularidade morfológico-gramatical) (MORAIS, 2003). Em termos práticos, no primeiro caso, o aluno precisa saber, por exemplo, que, para marcar um som de $r$ forte entre duas vogais, como em torre, ele precisa grafar $r r$, no segundo caso, para decidir se usa $s$ ou z em palavras como magreza e delicadeza, ele precisa aprender que, em substantivos derivados de adjetivos, usa-se \%:

Porém, quando não há regra que ajude o aprendiz, é preciso consultar modelos autorizados (como o dicionário) e memorizar, tendo em mente que "[...] a memorização da forma correta de palavras irregulares corresponde a conservar na mente as imagens visuais dessas palavras [...]", de modo que "[...] a exposição do aprendiz aos modelos de escrita correta das palavras que contêm irregularidades é fundamental para que ele memorize sua imagem visual" (MORAIS, 2003, p. 35). As explicações para as irregularidades ortográficas de determinadas palavras geralmente remetem à etimologia ou à tradição de uso, daí não existirem regras que possam ser inferidas quando é preciso escrever uma palavra que não se conhece ou cuja grafia não é lembrada no momento de escrever.

No que diz respeito à abordagem da ortografia no livro didático, Morais e Silva (2007) apontam alguns critérios a serem explorados pelo professor:

[...] examinar se o manual do professor apresenta considerações sobre a ortografia e sobre o seu ensino e aprendizagem; realizar um levantamento das correspondências letra-som que o livro didático propõe que se ensine em ortografia; examinar que atividades são propostas para ensinar ortografia; analisar se o livro didático trata diferentemente os casos regulares e irregulares da norma ortográfica; observar se existem atividades que exploram a 
segmentação de palavras; analisar como a acentuação de palavras é abordada (MORAIS; SILVA, 2007, p. 128).

Tradicionalmente, o ensino da ortografia é mais intenso nas séries iniciais da escolarização, já que o aluno precisa consolidar o código escrito. No entanto, o trabalho com a ortografia deve percorrer todas as séries escolares, pois se observa que um número considerável de alunos chega aos anos finais do Ensino Fundamental com acentuadas dificuldades de leitura, interpretação e produção de gêneros discursivos. As lacunas são de diversas naturezas, e entre elas está o domínio precário da norma ortográfica.

Sobre a abordagem da ortografia em livros didáticos, Silva (2010) destaca

[...] o esforço de desconstruir uma concepção de ensino de norma ortográfica restrita somente às séries iniciais, como se esse período fosse suficiente para o aprendizado da norma ortográfica. Questionamos a ideia de que tal objeto de conhecimento linguístico seria um produto acabado, cujo aprendizado se encerraria em um período curto, em um espaço definido no processo de escolarização. Contrariamente a essa perspectiva, concebemos que o ensino de ortografia deve ser contínuo, explicitado em todas as etapas da vida escolar (SILVA, 2010, p. 83).

Nessa perspectiva, os livros didáticos destinados às etapas finais do Ensino Fundamental também devem contemplar o ensino de ortografia de maneira abrangente e sistematizada, e não limitada a poucas seções, distribuídos em dois ou três capítulos do livro, contendo um ou dois exercícios em cada seção, muitos dos quais nem mesmo oferecem estímulo à apreensão das regras ou à construção de inferências sobre elas.

\section{Metodologia}

Este estudo pauta-se no objetivo de analisar o tratamento dado ao estudo da ortografia em uma coleção de livros didáticos destinada às séries finais do Ensino Fundamental. Constitui o corpus deste estudo a coleção Português: linguagens, em sua $9^{a}$ edição reformulada (2015), de autoria de William Roberto Cereja e Thereza Cochar Magalhães, publicado pela Editora Saraiva. Esse material consta do guia do Programa Nacional do Livro Didático (PNLD) de 2017-2019 e foi o escolhido para ser utilizado nesse triênio em grande parte das escolas da rede estadual de ensino na região Oeste do Paraná, o que justifica a análise de seu conteúdo, pois o estudo pode contribuir para a avaliação da coleção por parte dos professores das escolas públicas da região. Neste artigo, analisa-se mais detalhadamente o volume destinado ao $6^{\circ}$ ano, procedendo-se a uma descrição mais breve dos volumes posteriores $\left(7^{\circ}, 8^{\circ}\right.$ e $9^{\circ}$ anos). A ênfase no volume do $6^{\circ}$ ano se justifica pelo fato de se tratar do primeiro volume destinado ao segundo ciclo do Ensino Fundamental, momento em que os estudantes começam a ser requisitados a produzir textos com maior autonomia e de forma mais intensificada em relação ao que se exigia no ciclo anterior. 
Trata-se de uma pesquisa qualitativa, baseada em análise interpretativa dos dados, uma vez que as pesquisas realizadas na área da educação, com foco no ensino de língua, e, mais especificamente, sobre o livro didático, situam-se nesta perspectiva (LUDKE; ANDRE, 1986; VASCONCELOS, 2002). Para a coleta e tratamento de dados, utiliza-se a técnica da análise documental, de cunho interpretativo. Lüdke e André (1986) consideram a análise documental uma técnica importante na pesquisa qualitativa, seja para completar informações obtidas por outras técnicas, seja para desvendar aspectos novos de um tema ou problema. A opção por trabalhar com a pesquisa documental está relacionada ao fato de que os documentos são fontes naturais de informações que propiciam encontrar evidências capazes de fundamentar achados no decorrer da pesquisa (LÜDKE; ANDRÉ, 1986). Silva et al. (2009, p. 4557) também destacam, na pesquisa documental, a "relevância dos documentos de linguagem verbal e escrita, pois estes constituem os principais tipos de documentos na área da pesquisa educacional".

A análise dos materiais se baseia em critérios analíticos, com vista, principalmente, a identificar se as atividades propostas seguem procedimentos pautados nas seguintes categorias:

a) atividades de memorização: de caráter mais tradicional, envolvem questões cujos comandos são identificar palavras ou letras, circulá-las ou grifá-las, preencher lacunas, copiar um grupo de palavras para memorizar sua grafia, entre outros;

b) atividades de reflexão: fazem o aluno refletir sobre a grafia das palavras e não apenas memorizá-las ou identificá-las, a partir de questões cujos comandos envolvem realizar pesquisas, comparar e diferenciar escrita e enquadrar palavras em grupos a partir de uma constatação analítica do princípio gerativo (ou regra);

c) atividades de sistematização: possibilitam que o aluno, após uma série de outras atividades, de memorização ou reflexivas, consolide a regra explorada em determinada unidade didática.

Esses critérios guiaram o levantamento das atividades propostas no material didático em relação ao tópico "ortografia". Mais especificamente, para guiar a análise, elaborou-se um conjunto de questões, com base em Morais e Silva (2007) e Silva (2010):

1. O que o manual do professor revela sobre a abordagem da ortografia?

2. Há um ensino sistemático de ortografia ao longo das séries?

3. Há diferenciação de abordagem em relação às regularidades e irregularidades ortográficas no material?

4. Há um momento voltado à segmentação e à acentuação de palavras?

5. O material prioriza uma abordagem tradicional (baseada na memorização) ou uma abordagem reflexiva (baseada em reflexão sobre a regra)?

6. O material propõe atividades de sistematização do que foi aprendido? 


\section{Análise do corpus}

A coleção Português: linguagens é pautada, segundo anunciam seus autores, na perspectiva sociointeracionista da língua: “[...] pensamos que o ensino de português, hoje, deve abordar a leitura, a produção de texto e os estudos gramaticais sob uma mesma perspectiva de língua - a perspectiva enunciativa de língua, isto é, como meio de ação e interação social' (CEREJA; MAGALHÃES, 2015, p. 275)33.

Cada volume da coleção é dividido em quatro unidades, com três capítulos cada, divididos em seções, mais um capítulo extra (no final de cada unidade) denominado Intervalo, em que se propõe um projeto coletivo da classe. Ressalta-se que as seções não são uniformizadas nas unidades, nem em relação ao número de seções (entre três e seis cada capítulo), nem em relação à ordem em que aparecem. Abrem as unidades, além do título e imagens relativas ao tema desenvolvido, algumas sugestões de filmes, músicas, sítios eletrônicos e materiais de leitura sobre o tema. Os capítulos se iniciam com um texto, seguido da seção "Estudo do texto" (compreensão/interpretação e análise da linguagem do texto etc.) e/ou "Produção de texto" (prática de escrita de um gênero). Às vezes, há uma seção adicional com o trabalho de escrita ("Para escrever com expressividade", "Para escrever com adequação", "Para escrever com coerência e coesão", "Para escrever com técnica" etc.). A seção "A língua em foco" (geralmente a penúltima) destina-se ao trabalho com a gramática. Ocasionalmente, segue a seção "De olho na escrita", que trabalha questões como fonema e letra, divisão silábica, acentuação, ortografia etc. Finaliza cada capítulo, invariavelmente, a seção "Divirta-se", com uma atividade lúdica.

O Manual do Professor: Orientações Didáticas, no final de cada volume, contém: introdução; pressupostos teórico-metodológicos sobre o trabalho com a leitura, produção de texto, oralidade e gêneros orais, gramática (denominada "ensino da língua"), recursos complementares e articulação com outras áreas do conhecimento; avaliação (sobre o que avaliar em cada item - leitura, produção textual e gramática); estrutura e metodologia da obra (descrevendo o teor da unidades, capítulos e seções, com orientações sobre como explorá-los); cronograma; plano de curso, discriminando objetivos e conteúdos e indicando sugestões de estratégias; livro digital e multiletramento (sobre a tecnologia na escola).

Em uma análise mais geral da obra, verifica-se a incorporação de muitas das discussões teórico-metodológicas previstas nos documentos norteadores do ensino Língua Portuguesa. Nesse sentido, entre os aspectos observados no material, citam-se: a exposição abundante de gêneros variados; a proposição de atividades de compreensão de texto que não se restrinjam à localização de informações pontuais, mas incluam questões que promovem reflexão; o fornecimento de contexto para a produção escrita, com base em uma sequência de práticas anteriores destinadas ao estudo do texto que abre cada capítulo até chegar às atividades de produção de

3 As citações de Cereja e Magalhães (2015) apresentadas neste texto foram extraídas do volume do $6^{\circ}$ ano, exceto indicação contrária. 
texto propriamente ditas (ressalva-se que a produção de texto não é a parte final do capítulo, mas precede outras seções).

Conforme já mencionado, a ortografia é abordada na seção "De olho na escrita". O Manual, ao fazer referência a essa seção, traz apenas a seguinte nota ao professor:

\begin{abstract}
Nesta seção, os problemas notacionais da língua - ortografia e acentuação, por exemplo - recebem uma atenção especial, com trabalho contínuo e sistematizado. Em dois ou mais capítulos de cada unidade didática, o aluno desenvolve, pelo método indutivo, uma atividade relacionada ao assunto, inferindo as regras a partir das recorrências e pondo-as em prática (CEREJA; MAGALHÃES, 2015, p. 305).
\end{abstract}

A partir dessa breve descrição, pode-se identificar que os autores pretendem uma abordagem reflexiva, como propõem Morais (2003), Morais e Silva (2007) e Melo (2007). Uma crítica que se pode fazer, no entanto, é em relação à atenção que se dá ao trabalho com a ortografia. Constata-se, já no Manual, uma diferença em relação a outros tópicos apresentados: enquanto as orientações para o trabalho com os demais tópicos do ensino de Língua Portuguesa são acompanhadas de referencial teórico e sugestões de ampliação da atividade do capítulo, o trabalho com ortografia aparece sucintamente referido. $\mathrm{Na}$ mesma linha segue o tratamento no decorrer dos capítulos, como se verificará mais adiante: a abordagem da ortografia é exígua. Embora se afirme, no Manual, que o material dá "atenção especial" ao trabalho com ortografia, verifica-se, por exemplo, no livro do $6^{\circ}$ ano, que, em um total de doze capítulos, há apenas sete momentos destinados à ortografia, com cerca de três páginas de exposição, exemplificação e exercitação da norma ortográfica.

As seções "De olho na escrita" se estruturam da seguinte maneira: a) apresenta-se um texto ou fragmento de texto de algum gênero textual; b) propõemse algumas questões para trabalhar as características do gênero e/ou análise do conteúdo e questões que destacam palavras relacionadas ao tema da seção para análise de sua estrutura ou para inferência das regras; c) explicitam-se as regras e oferecem-se exemplos de uso; d) propõem-se novas questões para aplicação das regras.

No primeiro capítulo do volume do $6^{\circ}$ ano, a referida seção focaliza a distinção entre fonema e letra. É proposta uma atividade que, ao ser comparada às demais que tratam da ortografia, distingue-se positivamente, pois parte de um anúncio do Museu de Arte de São Paulo (Masp) e apresenta um trabalho inicial de reconhecimento do gênero, questionando a interlocução e a informatividade do texto, para depois abordar as relações entre sons e fonemas no texto verbal do anúncio. Para exemplificar, propõe a reflexão sobre a quantidade de letras e a respectiva quantidade de sons das palavras conta e que; na questão seguinte, sugere a comparação entre o som da letra $s$ nas palavras Masp e visite, que também fazem parte do anúncio.

$\mathrm{Na}$ sequência, há uma explanação sobre o conceito de fonema e sua representação. Seguem essa parte exercícios que exploram: a) a quantidade de 
letras e fonemas em palavras presentes em uma tira de Ziraldo (incluindo pares de letras que representam um único fonema); b) a identificação da vocalização do $l$ em final de palavras no português brasileiro; c) as correspondências fonêmicas da letra $x$; d) o reconhecimento da realização do fonema /s / na escrita. Destaca-se o último exercício, reproduzido a seguir, que promove reflexão sobre a relação entre fonemas e letras:

6. Com base nos exercícios anteriores, podemos chegar a três conclusões a respeito da relação entre os fonemas e as letras. Identifique os itens que expressam essas conclusões:

a) Um fonema pode ser representado na escrita por uma ou por várias letras.

b) Uma letra pode representar diferentes fonemas.

c) Um fonema será sempre representado por uma única letra.

d) Uma letra só pode representar um fonema.

e) A letra x pode representar dois fonemas: /ks/. (CEREJA; MAGALHÃES, 2015, p. 31).

Uma crítica que pode ser feita é com relação ao uso do texto como pretexto, tanto no caso do anúncio do Masp quanto no caso da tira de Ziraldo, para isolar elementos visando à análise, mas reconhece-se a dificuldade de abordar a ortografia sem isolar os elementos para focalizá-los na perspectiva de sua estrutura interna.

O trabalho com a ortografia não é proposto nos três capítulos seguintes, só reaparecendo no segundo capítulo da unidade 2. Nessa parte, verifica-se um conflito em relação à abordagem por meio de gêneros textuais, pois traz, em uma página inteira, um trecho de entrevista (gênero que ainda não foi apresentado aos estudantes até o momento nesse volume) e a utiliza apenas para retirar alguns vocábulos a fim de explicitar e exemplificar as noções de encontro consonantal e dígrafo, caracterizando-se, novamente, o uso do texto como pretexto. Nos três exercícios de fixação que seguem, são resgatadas algumas palavras do texto lido para identificação de encontros consonantais e dígrafos.

No capítulo 3 dessa mesma unidade, são apresentados os encontros vocálicos, e, para tal, faz-se uso de um poema de Paulo Netho. Novamente, o gênero fica relegado a fornecedor de palavras para análise de encontros vocálicos. Apresenta-se uma explanação sobre os conceitos de vogal, semivogal, hiato, ditongo e tritongo. Os exercícios propostos não privilegiam a reflexão ou a sistematização dos conteúdos, pois solicita do aluno, em dois dos três exercícios, a mera identificação e classificação de encontros vocálicos em palavras localizadas em um texto fornecido (texto informativo sobre a bússola). No último exercício, solicita-se que o aluno converse com os colegas sobre o modo de funcionamento e a utilidade da bússola.

$\mathrm{Na}$ unidade 3, os capítulos 2 e 3 apresentam propostas de trabalho com ortografia, sendo abordada, no capítulo 2, a divisão silábica, e no capítulo 3, a identificação de sílabas átonas, tônicas e a classificação das palavras quanto à tonicidade. O segundo capítulo usa uma curiosidade para explicar a separação de sílabas ao final da linha e novamente faz uso de um poema para exemplificar questões ortográficas. Para fixação do conteúdo ortográfico, há apenas um exercício que 
parte de uma tirinha e que está completamente descontextualizado dos três gêneros apresentados ao iniciar a discussão. Trata-se de uma lista de palavras aleatórias, que estão separadas em sílabas, em que há um vocábulo com as sílabas separadas em desacordo com as regras e que precisa ser identificado pelo aluno.

No capítulo da unidade 3 que aborda, conforme já referido, as sílabas tônica e átona, bem como a classificação das palavras, na língua portuguesa, de acordo com a tonicidade, a abordagem se inicia a partir de uma tira de Adão Iturrusgarai, em que aparece uma personagem revoltada com as normas ortográficas da língua portuguesa, questionando: "Por que 'tudo junto' se escreve separado e 'separado' se escreve tudo junto?" e "E a palavra 'palíndromo' deveria ser uma palíndromo". Primeiramente, solicita-se que o aluno identifique a sílaba mais forte de algumas palavras extraídas dessa tira, e, num segundo momento, propõe a discussão: "O que justifica a ortografia da língua?”. Há também uma questão sobre a caracterização do "palíndromo". Após a explanação sobre palavras oxítonas, paroxítonas e proparoxítonas, são propostos exercícios de fixação com base em um pequeno texto informativo sobre a água. O primeiro exercício explora o conteúdo do texto; os dois seguintes solicitam identificar a sílaba tônica de palavras extraídas do texto e classificar essas palavras em relação à tonicidade; e o último exercício solicita que o aluno, analisando as palavras estudadas nos exercícios anteriores, identifique a predominância da acentuação na pronúncia das palavras do português.

No capítulo 1 da unidade 4, aborda-se a acentuação de oxítonas, proparoxítonas e monossílabos tônicos. Nesse capítulo específico, os autores mostraram preocupação em elaborar questões que levem os estudantes à reflexão sobre os motivos de determinadas palavras levarem acento gráfico e outras não. Observa-se, nesse caso, uma abordagem indutiva da gramática, em que o aprendiz, a partir da análise dos elementos linguísticos, é capaz de inferir as regras. $\mathrm{Na}$ sequência, há boxes explicitando as regras de acentuação das oxítonas, dos monossílabos tônicos e das proparoxítonas, com a apresentação de exemplos. É interessante observar que tais regras são anunciadas da seguinte forma: "Conheça algumas regras de acentuação gráfica de acordo com a norma-padrão escrita" (CEREJA; MAGALHÃES, 2015, p. 223). Seguem-se três exercícios, que propõem: a) justificar o acento gráfico ou a ausência dele em palavras que aparecem em uma tira (têm e vem); b) completar frases com os verbos conter, manter, deter e reter na terceira pessoa (singular e plural) do presente do indicativo; e c) acentuar palavras em um texto, das quais foram retirados os acentos gráficos.

A ortografia volta a ser abordada no capítulo 3 dessa unidade, ainda trazendo como tema a acentuação das palavras, agora das paroxítonas. As atividades contemplam questões de identificação das paroxítonas em uma tira e de destaque daquelas que são acentuadas. Segue-se a explanação da regra de acentuação das paroxítonas, com exemplos, e mais três exercícios em que os alunos precisam acentuar adequadamente as palavras. 
Nos demais volumes ${ }^{4}$ da coleção Português: linguagens, são abordados os seguintes tópicos: a) no volume do $7^{\circ}$ ano: emprego do $g$ e do $j$ (em duas seções), acentuação dos ditongos e hiatos, uso do acento diferencial, emprego do há e do $a$, uso do mal e do mau, e uso do mas e do mais; b) no volume do $8^{\circ}$ ano: o emprego da letra $s$ (em duas seções), ortoépia e prosódia, emprego da letra ₹, uso do $x$ e do $c h$, e emprego do porque / por que / por quê / porquê (em duas seções); e c) no volume do $9^{\circ}$ ano: plural dos substantivos compostos, plural dos adjetivos compostos, adjetivos pátrios, uso de tem e têm / vem e vêm, emprego de $c /$ ç / ss, emprego de $e$ ou $i$ / o ou $u$, e emprego do pronome demonstrativo (em duas seções).

Nesses volumes, a abordagem da ortografia mantém-se similar à verificada no volume do $6^{\circ}$ ano. Observa-se que o trabalho com ortografia continua se limitando a poucos exercícios, alguns contextualizados com os gêneros do capítulo, e outros, completamente isolados do restante da unidade e dos gêneros nela abordados. Com frequência, são utilizados gêneros textuais para trabalhar meramente questões ortográficas, sem, contudo, propor uma reflexão sobre o gênero em questão, suas esferas de circulação, interatividade ou interlocução, limitando-se à proposição de algumas questões sobre o conteúdo ou à mera extração de palavras do texto, isolando-as para estudo. As questões ortográficas no decorrer dos volumes se apresentam alternando questões de memorização de regras e outras que levam o estudante a refletir sobre o uso de uma ou outra forma gráfica.

Algumas vezes, prioriza-se uma abordagem indutiva, geralmente partindo de textos (na maioria das vezes, uma tira) para analisar o emprego das palavras em foco no texto, mas há momentos em que o material propõe uma abordagem dedutiva (das regras para os exercícios), como ocorre, por exemplo, no livro do $7^{\circ}$ ano, na segunda seção destinada a tratar do uso de $g$ e $j$, em que se começa direto com as regras de uso do $g$.

Um exemplo de trabalho contextualizado e reflexivo se verifica na abordagem do emprego de há e $a$, no volume do $9^{\circ}$ ano, que parte de uma tira em que a personagem olha para uma foto de quando era jovem, e diz: “... Eu, há vinte anos atrás"; na sequência, olha para o espelho e, ao ver refletida uma face mais envelhecida, diz: “... Eu, daqui a vinte anos". As questões relacionadas trabalham com a interpretação do conteúdo e a inferência da regra de uso de há e $a$.

Outro exemplo digno de nota é quando se aborda, no mesmo volume, o uso do $e$ e $i /$ o e $u$. Não se trabalha a partir de exercícios mecânicos sem correspondência nenhuma com a realidade, mas se propicia refletir sobre a diferença entre a realização fonológica e a norma ortográfica:

$\mathrm{Na}$ língua portuguesa, nem sempre há correspondência entre os sons que produzimos na fala e as letras que os representam na escrita. É o caso, por

4 Conforme já anunciado, não é foco deste estudo a análise dos volumes destinados às demais séries $\left(7^{\circ}, 8^{\circ}\right.$ e $9^{\circ}$ anos), mas descreve-se brevemente seu conteúdo com o intuito de verificar quais aspectos da ortografia são abordados e se a abordagem do trabalho com a ortografia se mantém similar à verificada no volume do $6^{\circ}$ ano. 
exemplo, das vogais $e$ e $o$. quando elas são átonas, a tendência da língua oral é transformar o $e$ em $i$ e o $o$ em $u$. Assim, é comum a pronúncia mininu em vez de menino, mágua em vez de mágoa, ólio em vez de óleo, etc. (CEREJA; MAGALHÃES, 2015, p. 195) $)^{5}$.

De um modo geral, conforme se pôde observar na coleção como um todo, e mais especificamente, no volume destinado ao $6^{\circ}$ ano, a abordagem feita à ortografia não corresponde exatamente ao que o documento norteador de ensino (PCN) propõe, e tampouco recebe a "atenção especial" que o Manual do professor afirma que terá. Há poucas atividades que promovem a reflexão sobre as normas ortográficas, são raras as que sistematizam as regras e há lacunas com relação a outros tópicos relacionados à ortografia que deveriam ser também abordados por exemplo, não se encontra nenhuma atividade relacionada à segmentação não convencional das palavras.

\section{Consideraçóes finais}

Após a observação do material em questão, anuímos com Morais (2003) quando afirma que o ensino de ortografia não evoluiu nos últimos anos quando comparado a outros aspectos do ensino de Língua Portuguesa. Contudo, essa estagnação não deve ser atribuída apenas ao trabalho do professor ou à elaboração de manuais didáticos, pois tem, certamente, íntima relação com a falta de pesquisas e debates nessa área. Em eventos científicos e acadêmicos, raras são as referências ao tema, na atualidade, e mais raras ainda são publicações que apresentem teorias e novas abordagens metodológicas para que os docentes possam pautar sua prática nesse sentido.

É urgente que se tente reverter tal negligência com relação ao tema, pois, se, por um lado, a crença de que a aprendizagem da ortografia se daria naturalmente não se concretizou, por outro lado, a prática de sala de aula tem comprovado que o desconhecimento ortográfico ultrapassa os limites das produções escolares, propagando-se, por exemplo, em postagens de redes sociais e, inclusive, em notícias de jornais digitais com autores já adultos e suficientemente escolarizados. Fatos como esses exigem da escola e dos livros didáticos uma resposta, na perspectiva do que afirma Morais:

Tudo em ortografia é fruto de um acordo social, isto é, tudo foi arbitrado, mesmo quando existem regras que justificam por que em determinados casos temos que usar uma letra e não outra. Assim como não se espera que um indivíduo descubra sozinho as leis de trânsito - outro tipo de convenção social -, não há por que esperar que nossos alunos descubram sozinhos a escrita correta das palavras (MORAIS, 2003, p. 23).

Embora se possa afirmar que haja avanços no material, como, por exemplo, a abordagem indutiva em muitos momentos e o esforço direcionado para a inferência

5 Citação extraída do volume do $9^{\circ}$ ano. 
das regras e o entendimento do uso dessas regras pelo aluno, pode-se constatar, por outro lado, que a abordagem proposta pelo manual didático em questão não atende totalmente ao postulado pelos PCN. O próprio documento (PCN) avalia que "infelizmente, a ortografia ainda vem sendo tratada, na maioria das escolas do ensino fundamental, por meio de atividades de identificação, correção de palavra errada, seguidas de cópia e de enfadonhos exercícios de preenchimento de lacunas" (BRASIL, 1998, p. 85), e algumas dessas estratégias foram observadas no material didático analisado.

Acredita-se que as atividades de reflexão exigem sempre do aprendiz uma postura ativa em seu processo de aprendizagem ou aquisição ortográfica, levandoos a pensar diante das questões que lhe são propostas. Por essa razão, devem ser priorizadas no trabalho com a norma ortográfica.

Além disso, há necessidade de maior debate acerca do tema no meio acadêmico, pois, assim como nos materiais didáticos e no próprio fazer pedagógico dos professores de Língua Portuguesa, o estudo referente ao ensino da norma ortográfica tem ficado à margem das discussões.

\section{Referências}

BRASIL. Ministério da Educação. Secretaria de Educação Fundamental. Parâmetros Curriculares Nacionais: Língua Portuguesa. Secretaria de Educação Fundamental. Brasília: MEC/SEF, 1998.

BRASIL. Ministério da Educação. Base Nacional Comum Curricular. Brasília, s.d. Disponível em: < http://basenacionalcomum.mec.gov.br/download-da-bncc >. Acesso em: 30 nov. 2018.

CAGLIARI, Luiz Carlos. Alfabetização e ortografia. Educar, Curitiba, n. 20, p. 43 -58, 2002. Disponível em: <ojs.c3sl.ufpr.br/ojs2/index.php/educar/article/ view/2097>. Acesso em: 2 jun. 2018.

CEREJA, William Roberto; MAGALHÃES, Thereza Cochar. Português: linguagens. 9. ed. reform. São Paulo: Saraiva, 2015. 4 v.

LÜDKE, Menga; ANDRÉ, Marli Elisa Dalmazo Afonso de. Pesquisa em educação: abordagens qualitativas. São Paulo: EPU, 1986.

MELO, Kátia Leal Reis de. Refletindo sobre a ortografia em sala de aula. In: MORAIS, Artur Gomes de; SILVA, Alexsandro da; MELO, Kátia Leal Reis de. (Org.). Ortografia na sala de aula. Belo Horizonte: Autêntica, 2007. p. 77-94. Disponível em: <http:// www.serdigital.com.br/gerenciador/clientes/ceel/arquivos/25.pdf $>$. Acesso em: 2 jun. 2018.

MORAIS, Artur Gomes de. Ortografia: o que temos descoberto sobre esse objeto de conhecimento? O que é preciso investigar? Educação em Revista, Belo Horizonte, n. 31, p. 59-71, 2000. 
. Ortografia: ensinar e aprender. 4. ed. São Paulo: Ática, 2003. (Coleção Palavra de Professor).

; SILVA, Alexsandro da. Ensinando ortografia na escola. In: MORAIS, Artur Gomes de; SILVA, Alexsandro da; MELO, Kátia Leal Reis de. (Org.). Ortografia na sala de aula. Belo Horizonte: Autêntica, 2007. p. 61-76. Disponível em: <http://www. serdigital.com.br/gerenciador/clientes/ceel/arquivos/25.pdf $>$. Acesso em: 2 jun. 2018.

PARANÁ. Secretaria de Estado de Educação. Diretrizes Curriculares para a Educação Básica: Língua Portuguesa. Curitiba: SEED, 2008.

SILVA, Jorge Luís Lira da. O livro didático de Português pós-PNLD: como anda o ensino de ortografia? Cadernos de Educação, Pelotas, n. 35, p. 81-107, jan./abr. 2010.

SILVA, Lidiane Rodrigues Campêlo da et al. Pesquisa documental: alternativa investigativa na formação docente. Educere, Curitiba, p. 4554-4566, out. 2009. Disponível em: <http://educere.bruc.com.br/arquivo/pdf2009/3124_1712.pdf>. Acesso em: 30 nov. 2018.

VASCONCELOS, Silvia Inês Coneglian C. de. Pesquisas qualitativas e formação de professores de português. In: BASTOS, Neusa Barbosa (Org.). Língua Portuguesa: uma visão em mosaico. São Paulo: Cortez; PUC/SP/EDUC, 2002. p. 277-297. 